\title{
Edição científica e estímulo à pesquisa no campo da educação: o percurso do periódico Cadernos de História da Educação (2002-2021) ${ }^{1}$
}

Scientific editing and encouraging research in the field of education: the path of the periodical Cadernos de História da Educação (2002-2021)

Edición científica y estímulo a la investigación en el campo de la Educación: el trayecto del periódico Cuadernos de Historia de la Educación (2002-2021)

\author{
Décio Gatti Júnior \\ Universidade Federal de Uberlândia (Brasil) \\ Produtividade em Pesquisa do CNPq \\ Programa Pesquisador Mineiro da Fapemig \\ https://orcid.org/0000-0002-5876-6733 \\ http://lattes.cnpq.br/0164067095554570 \\ degatti@ufu.br
}

José Carlos Souza Araujo

Universidade Federal de Uberlândia (Brasil)

Universidade de Uberaba (Brasil)

https://orcid.org/0000-0002-7972-8875

http://lattes.cnpq.br/7069283169342231

jcaraujo.ufu@gmail.com

Carlos Henrique de Carvalho

Universidade Federal de Uberlândia (Brasil)

Produtividade em Pesquisa do CNPq

Programa Pesquisador Mineiro da Fapemig

https://orcid.org/0000-0002-8535-6828

http://lattes.cnpq.br/7463702480768930

chc@ufu.br
Wenceslau Gonçalves Neto

Universidade Federal de Uberlândia (Brasil)

Universidade de Uberaba (Brasil)

Produtividade em Pesquisa do CNPq Programa Pesquisador Mineiro da Fapemig https://orcid.org/0000-0002-4374-0311 http://lattes.cnpq.br/6258906373771462 wenceslau@ufu.br

Geraldo Inácio Filho

Universidade Federal de Uberlândia (Brasil)

https://orcid.org/0000-0003-0451-7851

http://lattes.cnpq.br/5354758011229936

geraldoinacio51@gmail.com

\footnotetext{
${ }^{1}$ As informações deste artigo proveem dos relatórios anuais de Cadernos de História da Educação apresentados na Universidade Federal de Uberlândia e das atividades de pesquisa desenvolvidas por Décio Gatti Júnior no projeto "Connecting History of Education. International networks, scientific production and global dissemination", com sede na Universidad de Valencia, Espanha, com apoio da Agencia Estatal de Investigación do Ministerio de Ciencia e Innovación da Espanha.
} 


\title{
Resumo
}

Trata-se da análise dos primeiros vinte anos de publicação do periódico científico Cadernos de História da Educação, entre 2002 e 2021. Iniciativa de um conjunto de pesquisadores do Núcleo de Estudos e Pesquisas em História e Historiografia da Educação, do Programa de PósGraduação em Educação, da Faculdade de Educação, da Universidade Federal de Uberlândia (UFU), com sede no Estado de Minas Gerais, no Brasil. Neste artigo são apresentadas informações gerais sobre o periódico, elementos de sua situação atual, histórico básico, artigos e dossiês publicados, idiomas de publicação, países e combinação de países estudados, vinculações institucionais dos autores, épocas históricas abordadas. Ao final, estão apontados os principais progressos obtidos ao longo dos anos e os desafios para a continuidade e para o incremento da qualidade do periódico.

Palavras-chave: História. Educação. Edição científica. Cadernos de História da Educação.

\begin{abstract}
This is an analysis of the first twenty years of publication of the scientific periodical Cadernos de História da Educação, from 2002 to 2021. It has been the initiative of a group of researchers of the Study and Research Group in History and Historiography of Education, of the Graduate Studies Program in Education, and of the School of Education of the Universidade Federal de Uberlândia (UFU) in the state of Minas Gerais, Brazil. This article provides general information regarding the journal, elements of its current situation, basic history, articles and dossiers published, languages of publication, countries and combinations of countries studied, institutional affiliations of authors, and historical periods examined. The article concludes by indicating the main advances achieved over the years and the challenges for continuity and for increasing the quality of the periodical.
\end{abstract}

Keywords: History. Education. Scientific editing. Cadernos de História da Educação.

\section{Resumen}

Se trata de un análisis de los primeros veinte años de publicación del periódico científico: Cuadernos de Historia de la Educación, entre 2002 y 2021. Iniciativa de un conjunto de investigadores del Núcleo de Estudios e Investigaciones en Historia e Historiografía de la Educación del programa de Posgrado en Educación, de la Facultad de Educación, de la Universidad Federal de Uberlândia (UFU), con sede en el Estado de Minas Gerais, en Brasil. En este artículo son presentados aspectos generales sobre el periódico, informe de su situación actual, histórico básico, artículos y dosieres publicados, idiomas de publicación, países y combinación de países estudiados, vinculaciones institucionales de los autores y épocas históricas abordadas. Finalmente, se señalan los principales progresos obtenidos a lo largo de los años y los desafíos para la continuidad y el incremento de la calidad del periódico.

Palabras clave: Historia. Educación. Edición científica. Cuadernos de Historia de la Educación. 
O periódico Cadernos de História da Educação teve seu primeiro volume publicado no ano de 2002. Seu vigésimo volume foi publicado neste ano de 2021, quando se comemoram vinte anos de sua existência. Empreendimento este que resultou e ainda resulta dos esforços de um conjunto de professores e de pesquisadores que compõem o Núcleo de Estudos e Pesquisas em História e Historiografia da Educação, do Programa de PósGraduação em Educação, da Faculdade de Educação, da Universidade Federal de Uberlândia (UFU), com sede no Estado de Minas Gerais, no Brasil.

Neste texto são apresentadas informações gerais sobre o periódico, o que inclui: elementos de sua situação atual, histórico básico; artigos e dossiês publicados; idiomas de publicação, países e combinação de países estudados; vinculações institucionais dos autores; épocas históricas abordadas. Ao final, estão apontados os principais progressos obtidos ao longo dos anos e os principais desafios para a continuidade e para o incremento da qualidade de Cadernos de História da Educação.

\section{Situação atual e percurso histórico}

Atualmente, o periódico possui seções fixas destinadas à publicação de artigos, de resenhas de livros recentemente publicados e de documentos de interesse para a História da Educação. Além disso, publicam-se frequentemente dossiês temáticos, os quais abordam temáticas específicas, sob a coordenação de um ou dois pesquisadores da área de História da Educação, com autores necessariamente vinculados a instituições no Brasil e no exterior. Eventualmente, são publicadas entrevistas com pesquisadores proeminentes da área de Educação, de História e, principalmente, de História da Educação.

Desde o início da publicação foram publicados artigos em português e em espanhol. Em 2009, o periódico passou a publicar artigos redigidos em francês e inglês. Em 2014, foi acrescentado o italiano como idioma oficial da revista. Desde 2019, tornou-se norma que os artigos fossem publicados em edição bilíngue, no idioma original e em inglês, o que se consolidou em 2020 e prossegue atualmente. Nos casos em que o idioma original seja o inglês, a versão em português também poderá ser publicada. Em todos os casos, procurar-se-á, na medida do possível, que os textos sempre tenham publicadas versões em português ou espanhol, idiomas de acesso mais fácil e frequente à maior parte dos leitores do periódico. Em qualquer caso, porém, há necessidade de os artigos publicados apresentarem títulos, resumos e palavras-chave em inglês e em espanhol. Por vezes, são publicadas traduções de textos importantes para além da área de História da Educação que não constam em português, com menção à publicação original.

O periódico está indexado na Bibliografia Brasileira de Educação (BBE), do Ministério da Educação do Brasil; no Directory Indexing of International Research Journals (Citefactor), mantido em colaboração por instituições do Canadá e dos Estado Unidos; na Fundación Dialnet (Dialnet), da Universidad de La Rioja, na Espanha; no Directory of Open Access Journals (DOAJ), mantido pela Lund University, na Suécia; no Educ@. Publicação On Line de Educação (Metodologia Scielo), da Fundação Carlos Chagas, no Brasil; no Portal de Periódicos da Coordenação de Aperfeiçoamento de Pessoal de Nível Superior (Capes), do Ministério da Educação (MEC), no Brasil; no ProQuest Education Database, com sede em Ann Arbor, Michigan, nos Estados Unidos; no Repertório Científico de Acesso Aberto de Portugal (RCAAP), em Portugal; no Sistema Regional de Información em Línea para Revistas Científicas de América Latina, el Caribe, Espanã y Portugal (Latindex), com sede na Universidad Nacional Autónoma de México (Unam); Sumários de Revistas Brasileiras (Sumários.org), mantido pela Fundação de Pesquisas Científicas de Ribeirão Preto (Funpec-RP), no Brasil; Periódicos de Minas - 
Portal de Periódicos Científicos e Tecnológicos do Estado de Minas Gerais, mantido pela Fundação de Amparo à Pesquisa do Estado de Minas Gerais (Fapemig).

Além disso, o periódico está preservado na Rede Cariniana, mantida pelo Instituto Brasileiro de Informação em Ciência e Tecnologia (Ibict), vinculado ao Ministério da Ciência, Tecnologia e Inovações (MCTI), no Brasil; no Keepers Registry, mantido pela Universidade de Edimburgo, na Escócia, no Reino Unido, em parceria com o International Standard Serial (ISSN), em Paris, na França; no Public Knowledge Projetc (PKP), vinculado ao Open Archives Harvester.

Desde 2008, o periódico está classificado no estrato A2 da área de Educação do Qualis/CAPES, que é o segundo estrato mais alto de uma escala que possui oito níveis de classificação e que subsidia o processo de avaliação dos programas de pós-graduação em Educação no país. Além disso, desde 2020, o periódico foi classificado no nível A, o mais alto, na avaliação promovida pela Agenzia Nazionale di Valutazione del Sistema Universitario e della Ricerca (Anvur), na Itália, com acesso em: https://www.anvur.it/.

Desde 2017, o periódico passou a contar com editores associados, por idioma, a saber: para os países de língua portuguesa, exceto o Brasil, os colegas de Portugal, Prof. Dr. Joaquim Pintassilgo (Universidade de Lisboa) e Prof. Dr. Luís Alberto Marques Alves (Universidade do Porto); para os países de língua inglesa, os colegas dos Estados Unidos, Prof. Dr. Karl Lorenz (Sacred Heart University) e Prof. Dr. Noah W. Sobe (Loylola University Chicago); para os países de língua espanhola, os colegas da Espanha, Prof. Dr. Antón Costa Rico (Universidade de Santiago de Compostela) e Prof. Dr. Miguel Somoza Rodríguez (Universidad Nacional de Educación a Distancia). A colaboração destes colegas tem favorecido o incremento do processo de internacionalização do periódico.

Atualmente, o Conselho Editorial do periódico, que se dedica ao estabelecimento das políticas editoriais, ao envio de propostas de publicação e à emissão de pareceres, é composto por 37 pesquisadores do Brasil e do exterior, provenientes de 14 países, a saber: Alemanha, Argentina, Bélgica, Brasil, Canadá, Chile, Espanha, Estados Unidos, França, Itália, México, Portugal, Reino Unido e Uruguai. Além disso, o Conselho Consultivo, que se dedica principalmente à emissão de pareceres sobre as propostas de publicação recebidas, é integrado por 44 pesquisadores, principalmente, brasileiros, mas, também, estrangeiros, notadamente da Argentina, da Espanha e de Portugal.

Em termos de histórico, a emergência de um grupo de pesquisa em História da Educação na Universidade Federal de Uberlândia no início da década de 1990, permitiu a criação de uma linha de pesquisa dedicada à História e à Historiografia da Educação no âmbito do Programa de Pós-Graduação em Educação da Universidade Federal de Uberlândia (UFU). Ambas iniciativas na área de História da Educação levaram à necessidade de divulgação dos resultados de pesquisa alcançados, sendo que, até então, a produção científica era veiculada principalmente no Boletim do Centro de Documentação e Pesquisa em História da UFU (Cdhis/UFU), mas, com o passar do tempo, o volume de publicações excedeu a capacidade do referido Boletim, o que oportunizou a criação, em 2002, do periódico Cadernos de História da Educação.

Em um primeiro momento, o periódico seria apenas um canal de divulgação dos resultados de investigações desenvolvidas por pesquisadores da UFU, objetivo logo abandonado, devido à emergência de um complexo sistema de avaliação de periódicos, nomeado por Qualis, desenvolvido no âmbito da Capes, que é a agência estatal responsável pela avaliação da pós-graduação no Brasil.

Deste modo, o periódico buscou atender aos critérios de qualidade provenientes do Qualis/Capes, especificamente daqueles fixados pela área de Educação, o que lhe possibilitou alcançar avaliações positivas desde logo, sendo que, em 2008, o periódico foi classificado no estrato A2 do Qualis/CAPES (Área de Educação), em uma escala que compreendia os seguintes estratos: C (mais baixo), B5, B4, B3, B2, B1, A2 e A1 (mais alto). 
O periódico, até o presente momento, mantém-se classificado no estrato A2. Todavia, entre 2020 e 2021, houve mudanças no sistema de avaliação, com adoção do padrão de qualidade vinculado mais diretamente ao índice de citações, com uma nova escala avaliativa, a saber: C (mais baixo), B4, B3, B2, B1, A4, A3, A2, A1 (mais alto). Em princípio, os resultados deverão ser divulgados no início de 2022.

Em termos de periocidade, de 2002 a 2008, a publicação foi anual, com passagem a semestral em 2009 e a quadrimestral em 2015. Desde este ano de 2021, adotou-se o formato de publicação contínua, o que visou conferir mais agilidade ao processo de submissão, avaliação e publicação de propostas no periódico. Atualmente, o periódico publica entre 45 e 60 artigos anualmente, incluindo ainda documentos de interesse histórico-educacional e resenhas de livros recentemente publicados da área de História da Educação.

Desde 2008, o periódico passou a ter seus números publicados integralmente na Internet, por meio da versão brasileira do Open Journal Sistem (OJS), com acesso no seguinte endereço: http://www.seer.ufu.br/index.php/che/, que permanece até o presente momento. É importante destacar que desde 2008 todos os volumes publicados pelo periódico constam completos e na modalidade de acesso aberto integral na referida página do periódico no OJS.

Desde o início de sua publicação, Cadernos de História da Educação conta com o apoio da Editora da Universidade Federal de Uberlândia (Edufu) e, a partir de 2010, passou a contar também com o apoio da Fapemig, o que se manteve para o biênio 2020-2021. A partir de 2021, os periódicos publicados pela UFU passaram da vinculação à Edufu para a Biblioteca da UFU.

O projeto gráfico da capa conferiu identidade ao periódico desde o início de sua publicação, seja pelo formato, quando da existência da versão impressa, maior que o usual, mas, também, pela inclusão na capa de uma imagem fotográfica vinculada a momentos históricoeducacionais da região do Triângulo Mineiro e Alto Paranaíba, em Minas Gerais, no Brasil.

Nessa direção, as fotografias demonstravam a universalidade do fenômeno da escolarização, sem deixar de guardar referência com o lugar de origem do periódico. Deste modo, vigorou um projeto gráfico nos primeiros dez anos do periódico e, em seguida, um outro projeto foi implantado, sem, no entanto, perder a identidade original, conforme pode ser verificado nas Figuras 1 e 2.

Figura 1 - Capa do Volume 1, Número 1, Janeiro a Dezembro de 2002, do periódico Cadernos de História da Educação.

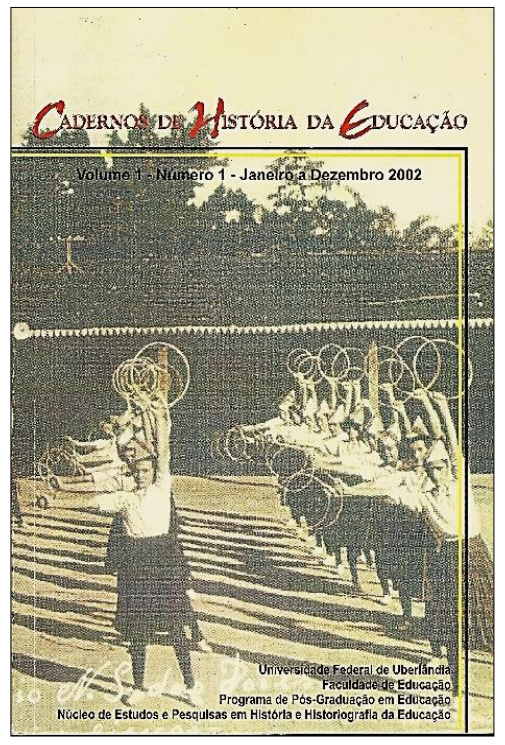

Figura 2 - Capa do Volume 20, 2021 (Publicação contínua), do periódico Cadernos de História da Educação.

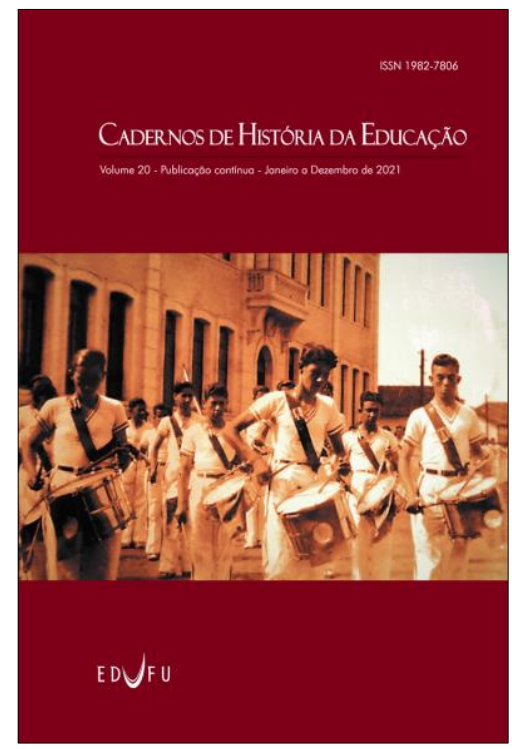


Artigos e dossiês: quantitativos, idiomas, países, autores, instituições e épocas históricas

Nesses primeiros vinte anos, o periódico publicou 653 artigos, 500 deles, em fluxo contínuo e 153 deles em 26 diferentes dossiês temáticos, conforme pode ser examinado nas Tabelas 1 e 2 expostas a seguir.

Tabela 1 - Artigos publicados em Cadernos de História da Educação (2002-2021)

\begin{tabular}{|c|c|c|c|c|}
\hline Volume & Ano & Artigos (fluxo contínuo) & Artigos (dossiês) & Subtotal \\
\hline 1. & 2002 & 23 & 00 & 23 \\
\hline 2. & 2003 & 5 & 10 & 15 \\
\hline 3. & 2004 & 4 & 12 & 16 \\
\hline 4. & 2005 & 16 & 00 & 16 \\
\hline 5. & 2006 & 4 & 08 & 12 \\
\hline 6. & 2007 & 14 & 00 & 14 \\
\hline 7. & 2008 & 11 & 08 & 19 \\
\hline 8. & 2009 & 28 & 00 & 28 \\
\hline 9. & 2010 & 31 & 00 & 31 \\
\hline 10. & 2011 & 29 & 06 & 35 \\
\hline 11. & 2012 & 34 & 00 & 34 \\
\hline 12. & 2013 & 33 & 05 & 38 \\
\hline 13. & 2014 & 26 & 11 & 37 \\
\hline 14. & 2015 & 33 & 17 & 50 \\
\hline 15. & 2016 & 32 & 18 & 50 \\
\hline 16. & 2017 & 35 & 11 & 46 \\
\hline 17. & 2018 & 29 & 16 & 45 \\
\hline 18. & 2019 & 32 & 12 & 44 \\
\hline 19. & 2020 & 45 & 12 & 57 \\
\hline 20. & 2021 & 36 & 07 & 43 \\
\hline & Total & $\mathbf{5 0 0}$ & $\mathbf{1 5 3}$ & $\mathbf{6 5 3}$ \\
\hline
\end{tabular}

Tabela 2 - Dossiês temáticos publicados em Cadernos de História da Educação (2002-2021)

\begin{tabular}{|c|c|l|}
\hline Ano & Número & \multicolumn{1}{c|}{ Títulos dos dossiês publicados } \\
\hline 2003 & 1. & História das Instituições Escolares I \\
\hline 2004 & 2. & História das Instituições Escolares II \\
\cline { 2 - 3 } 2 & 3. & História das Disciplinas Escolares \\
\hline \multirow{2}{*}{2006} & 4. & $\begin{array}{l}\text { Tempo de Cidade, Lugar de Escola e de Cultura no Espaço-Portugal- } \\
\text { Brasil: dinâmicas institucionais, axiológicas, culturais, simbólicas e de } \\
\text { formação de professores }\end{array}$ \\
\cline { 2 - 4 } & \multirow{2}{*}{5.} & $\begin{array}{l}\text { Imprensa de Educação e Ensino, Educação Popular e Formação do Campo } \\
\text { Pedagógico na primeira metade do Século XX }\end{array}$ \\
\hline 2008 & 6. & A História da Educação em Minas Gerais: investigações recentes \\
\hline 2011 & 7. & A Pesquisa em História da Educação em Perspectiva Internacional \\
\hline 2013 & 8. & Instrumentos do trabalho didático \\
\hline \multirow{2}{*}{2014} & 9. & $\begin{array}{l}\text { O ensino de História da Educação no espaço luso-brasileiro: percursos } \\
\text { institucionais, currículos e manuais disciplinares }\end{array}$ \\
\cline { 2 - 4 } & 10. & Dimensões laico e religiosas no espaço Luso-Brasileiro nos séculos XIX e XX \\
\hline \multirow{2}{*}{2015} & 11. & $\begin{array}{l}\text { A invenção da América: estudos sobre Educação, História e Cultura na } \\
\text { América Latina (1879-1950) }\end{array}$ \\
\cline { 2 - 3 } & 12. & História da Educação e História Regional Paulista \\
\cline { 2 - 3 } & 13. & Colégio Pedro II - lugar de memória da educação brasileira \\
\hline
\end{tabular}




\begin{tabular}{|c|c|l|}
\hline \multirow{2}{*}{2016} & 14. & $\begin{array}{l}\text { História oral: narrativas de memória, acervos e a pesquisa em História da } \\
\text { Educação }\end{array}$ \\
\cline { 2 - 3 } & 15. & Experimentalismo no Ensino Secundário nos anos 1950 e 1960 \\
\cline { 2 - 3 } 2017 & 16. & Tópicos de História da Educação nos Estados Unidos (entre os séculos XIX e XX) \\
\cline { 2 - 3 } & 17. & $\begin{array}{l}\text { História da Educação Matemática e Formação de Professores que Ensinam } \\
\text { Matemática }\end{array}$ \\
\hline \multirow{2}{*}{2018} & 18. & Produção de conhecimentos, difusão e ensino na (e da) História da Educação \\
\cline { 2 - 4 } & 19. & Manuais escolares, mediações tecnológico-pedagógicas da Escola Moderna \\
\cline { 2 - 4 } & 20. & Educação de Mulheres no Brasil e em Portugal (séculos XIX e XX) \\
\hline \multirow{2}{*}{2019} & 21. & $\begin{array}{l}\text { Educação e Espaço Público em experiências históricas latino-americanas } \\
\text { (Séculos XIX-XX) }\end{array}$ \\
\hline \multirow{2}{*}{2020} & 22. & Educação em Perspectiva Local/Municipal \\
\cline { 2 - 3 } & 24. & Escolarização, livros escolares e movimentos migratórios \\
\hline 2021 & 25. & Foucault, a genealogia, a história da educação \\
\hline
\end{tabular}

De um início mais modesto, com publicação anual de aproximadamente 15 artigos, chegou-se, nos últimos anos, ao triplo, com cerca de 45 artigos publicados anualmente, ao que se deve acrescentar a publicação atualmente da totalidade dos artigos em versão bilíngue, com predominância de artigos em português/inglês. Em termos de idioma, o predomínio tem sido de artigos publicados em português $(72,64 \%)$ e, devido à implementação da política de publicação bilíngue desde 2019, consta em segundo lugar a publicação de artigos em português/inglês $(19,23 \%)$. Depois, em terceiro lugar, aparece a publicação em espanhol e em espanhol/inglês, que perfazem $6,14 \%$ do total. O inglês como idioma de publicação atingiu $1,2 \%$ do total, seguido do italiano/inglês $(0,4 \%)$, do italiano $(0,13 \%)$ e do francês $(0,13 \%)$, conforme pode ser examinado na Tabela 3 a seguir. Note-se que a veiculação dos artigos em inglês, somada aos artigos bilíngues, alcança 21,63\% dos artigos publicados entre 2002 e 2021.

Tabela 3 - Idiomas dos artigos publicados em Cadernos de História da Educação (2002-2021)

\begin{tabular}{|l|c|c|}
\hline \multicolumn{1}{|c|}{ Idioma/Combinação de idiomas } & Número de artigos & $\mathbf{\%}$ \\
\hline Português & 544 & 72,64 \\
\hline Português/Inglês (bilíngue) & 144 & 19,23 \\
\hline Espanhol & 41 & 5,47 \\
\hline Inglês & 09 & 1,20 \\
\hline Espanhol/Inglês (bilíngue) & 05 & 0,67 \\
\hline Italiano/Inglês (bilíngue) & 03 & 0,40 \\
\hline Italiano & 01 & 0,13 \\
\hline Francês & 01 & 0,13 \\
\hline Português/Inglês/Espanhol (trilíngue) & 01 & 0,13 \\
\hline
\end{tabular}

No que se refere aos objetos de estudo priorizados, leia-se, países e combinação de países, bem como artigos relacionados a abordagens conceituais, historiográficas, ao ensino de História da Educação e ao tema do patrimônio histórico-educativo, no período de 2002 a 2021, o Brasil foi o tema de estudo privilegiado $(69,34 \%)$. Depois, os artigos priorizaram temas conceituais ou historiográficos $(10,06 \%)$. Em terceiro lugar, consta Portugal $(5,66 \%)$, seguido por Espanha (1,89\%), Estados Unidos (1,72\%), Chile (1,57\%) e Argentina (1,09\%). Os estudos comparados também apareceram e somaram 2,53\%, a saber: Brasil/Argentina, Brasil/França, Brasil/Paraguai, Brasil/Portugal/França/Espanha, Brasil/Venezuela e Brasil/Espanha. As temáticas do ensino de História da Educação e do patrimônio educativo compareceram juntas 
em nono lugar (1,09\%). Com percentuais menores, podemos citar: Itália, Colômbia, França, México, Uruguai, Venezuela. Com apenas um ou dois artigos publicados, constam como objeto de estudo: Grécia, Nigéria, Angola, Bélgica, Paraguai e Suíça. Os dados completos podem ser observados na Tabela 4 exposta a seguir.

Tabela 4 - Objetos de estudo priorizados em Cadernos de História da Educação (2002-2021)

\begin{tabular}{|l|c|c|}
\hline Lugar (país, combinação de países ou temas gerais) & Incidências & $\mathbf{\%}$ \\
\hline Brasil & 441 & 69,34 \\
\hline Abordagem conceitual e/ou historiográfica & 64 & 10,06 \\
\hline Portugal & 36 & 5,66 \\
\hline Espanha & 12 & 1,89 \\
\hline Estados Unidos & 11 & 1,72 \\
\hline Chile & 10 & 1,57 \\
\hline Brasil/Portugal & 10 & 1,57 \\
\hline Argentina & 9 & 1,40 \\
\hline Ensino de História da Educação ou Patrimônio Educativo & 7 & 1,09 \\
\hline Itália & 5 & 0,79 \\
\hline Colômbia & 4 & 0,63 \\
\hline França & 4 & 0,63 \\
\hline México & 3 & 0,47 \\
\hline Uruguai & 3 & 0,47 \\
\hline Venezuela & 3 & 0,47 \\
\hline Grécia & 2 & 0,32 \\
\hline Nigéria & 2 & 0,32 \\
\hline Angola & 1 & 0,16 \\
\hline Bélgica & 1 & 0,16 \\
\hline Paraguai & 1 & 0,16 \\
\hline Suíça & 1 & 0,16 \\
\hline Brasil/Argentina & 1 & 0,16 \\
\hline Brasil/França & 1 & 0,16 \\
\hline Brasil/Paraguai & 1 & 0,16 \\
\hline Brasil/Portugal/França/Espanha & 1 & 0,16 \\
\hline Brasil/Venezuela & 1 & 0,16 \\
\hline Brasil/Espanha & 1 & 0,16 \\
\hline
\end{tabular}

Quanto aos países de procedência dos autores que publicaram artigos durante os primeiros vinte anos de existência de Cadernos de História da Educação, entre 2002 e 2021, o predomínio de brasileiros é evidente, da ordem de $84,3 \%$. Todavia, neste caso é preciso lembrar da dimensão continental que possui o Brasil, o que fica demonstrado pelo número de instituições de diferentes estados e municípios brasileiros de procedência dos autores, o que alcançou 131 universidades ou instituições de pesquisa e ensino. Em seguida, predominaram autores de Portugal (5,39\%). Com alguma distância, autores da Argentina $(1,76 \%)$, da Espanha (1,17\%), dos Estados Unidos (0,89\%), do Chile (0,89\%), da Itália $(0,69 \%)$ e da Colômbia $(0,59 \%)$. Na sequência, com números de autores entre $6(0,39 \%)$ e $1(0,1 \%)$, em ordem decrescente, houve autores do México, da Bélgica, da Nigéria, da França, do Uruguai, da Grécia, da Hungria, da Inglaterra, da Polônia e da Venezuela. Além disso, é importante destacar que ocorreram combinação de dois ou mais autores de um mesmo artigo, provavelmente, como resultado de investigações desenvolvidas de modo interinstitucional e internacional, notadamente: Brasil/Portugal (1,37\%), Brasil/Colômbia $(0,39 \%)$, Brasil/Itália (0,20\%), Brasil/Estados Unidos $(0,20 \%)$ e Brasil/Espanha $(0,20 \%)$. As informações detalhadas constam na tabela 5 exposta a seguir. 
Tabela 5 - Procedência dos/as autores/as em Cadernos de História da Educação (2002-2021)

\begin{tabular}{|c|l|c|c|}
\hline Número de países & País/Combinação de países & Número de autores & \% \\
\hline 1. & Brasil & 861 & 84,30 \\
\hline 2. & Portugal & 55 & 5,39 \\
\hline 3. & Argentina & 18 & 1,76 \\
\hline 4. & Brasil/Portugal & 14 & 1,37 \\
\hline 5. & Espanha & 12 & 1,17 \\
\hline 6. & Estados Unidos & 9 & 0,89 \\
\hline 7. & Chile & 9 & 0,89 \\
\hline 8. & Itália & 7 & 0,69 \\
\hline 9. & Colômbia & 6 & 0,59 \\
\hline 10. & México & 4 & 0,39 \\
\hline 11. & Brasil/Colômbia & 4 & 0,39 \\
\hline 12. & Bélgica & 3 & 0,29 \\
\hline 13. & Nigéria & 3 & 0,29 \\
\hline 14. & França & 3 & 0,29 \\
\hline 15. & Uruguai & 2 & 0,20 \\
\hline 16. & Brasil/Itália & 2 & 0,20 \\
\hline 17. & Brasil/Estados Unidos & 2 & 0,20 \\
\hline 18. & Brasil/Espanha & 2 & 0,20 \\
\hline 19. & Grécia & 1 & 0,10 \\
\hline 20. & Hungria & 1 & 0,10 \\
\hline 21. & Inglaterra & 1 & 0,10 \\
\hline 22. & Polônia & 1 & 0,10 \\
\hline 23. & Venezuela & 1 & 0,10 \\
\hline
\end{tabular}

No que se refere ao número de universidades e de instituições de pesquisa e ensino às quais se vinculam os autores dos artigos publicados em Cadernos de História da Educação, entre 2002 e 2021, houve predominância do Brasil, com 131 instituições, o que perfaz 65,18\% do total, com destaque para dez universidades com maior número de autores registrados, a saber: Universidade Federal de Uberlândia, Universidade de São Paulo, Universidade Federal de Pelotas, Universidade Federal de Minas Gerais, Universidade Estadual Paulista, Universidade Estadual de Maringá, Universidade do Estado do Rio de Janeiro, Universidade de Uberaba, Universidade Federal de Ouro Preto e Universidade Federal do Rio Grande do Sul. Todavia, é abrangente a presença de universidades e instituições brasileiras, o que expressa excelente nível de diversidade regional e estadual.

Em seguida, consta Portugal, com 16 instituições (7,98\%), destacadamente: Universidade de Lisboa, Universidade de Coimbra, Universidade do Porto; Universidade do Minho. Depois, a Argentina, com 10 instituições (4,99\%), principalmente: Universidad de Buenos Aires, Universidade Nacional de La Plata e Universidad Nacional de Entre Rios.

A Espanha compareceu com 09 instituições (4,49\%), com destaque para a Universidade de Santiago de Compostela e a Universidad de Sevilla. Dos Estados Unidos, houve autores vinculados a 6 instituições (2,99\%), entre as quais: Sacred Heart University, Utah State University, Loyola University Chicago e Stanford University.

Da Itália, constam autores de 5 instituições $(2,49 \%)$, principalmente, da Università degli Studi del Molise e da Università degli Studi di Macerata. Depois, entre 4 e 1 instituições, constam: Chile, México, Colômbia, França, Bélgica, Nigéria, Grécia, Hungria, Inglaterra, Polônia, Uruguai e Venezuela. Os dados gerais sobre os países e o número de instituições podem ser examinados na Tabela 6 exposta a seguir. 
Tabela 6 - Países e instituições dos autores de Cadernos de História da Educação (2002-2021)

\begin{tabular}{|c|l|c|r|}
\hline Número de países & \multicolumn{1}{|c|}{ Países } & Número de Instituições & \% \\
\hline 1. & Brasil & 131 & 65,18 \\
\hline 2. & Portugal & 16 & 7,98 \\
\hline 3. & Argentina & 10 & 4,99 \\
\hline 4. & Espanha & 9 & 4,49 \\
\hline 5. & Estados Unidos & 6 & 2,99 \\
\hline 6. & Itália & 5 & 2,49 \\
\hline 7. & Chile & 4 & 1,99 \\
\hline 8. & México & 4 & 1,99 \\
\hline 9. & Colômbia & 3 & 1,49 \\
\hline 10. & França & 3 & 1,49 \\
\hline 11. & Bélgica & 2 & 0,99 \\
\hline 12. & Nigéria & 2 & 0,99 \\
\hline 13. & Grécia & 1 & 0,49 \\
\hline 14. & Hungria & 1 & 0,49 \\
\hline 15. & Inglaterra & 1 & 0,49 \\
\hline 16. & Polônia & 1 & 0,49 \\
\hline 17. & Uruguai & 1 & 0,49 \\
\hline 18. & Venezuela & 1 & 0,49 \\
\hline \multicolumn{2}{|c|}{ Total } & $\mathbf{2 0 1}$ & $\mathbf{1 0 0 \%}$ \\
\hline
\end{tabular}

Os artigos publicados em Cadernos de História da Educação no período compreendido entre 2002 e 2021 deixam evidente que a época mais abordada foi o Século 20, o que alcançou $69,8 \%$ dos artigos publicados. Em seguida consta o Século 19, com 14,54\% dos artigos publicados e, depois, o período compreendido entre os séculos 19 e 20. Somadas os três, têmse robustos $93,07 \%$ da concentração da época de estudos dos autores publicados entre os séculos 19 e 20. As demais épocas aparecem dispersas entre o Século 3 e 21, conforme pode ser examinado na Tabela 7 exposta a seguir.

Tabela 7 - Períodos históricos abordados em Cadernos de História da Educação (2002-2021)

\begin{tabular}{|c|c|c|}
\hline Século(s) & Número de artigos & \% \\
\hline 21 & 3 & 0,55 \\
\hline $20-21$ & 10 & 1,80 \\
\hline 20 & 384 & 69,80 \\
\hline $19-20$ & 48 & 8,73 \\
\hline 19 & 80 & 14,54 \\
\hline $18-20$ & 2 & 0,37 \\
\hline $18-19$ & 1 & 0,18 \\
\hline 18 & 6 & 1,10 \\
\hline $17-18$ & 2 & 0,37 \\
\hline 17 & 1 & 0,18 \\
\hline $16-20$ & 2 & 0,37 \\
\hline $16-19$ & 1 & 0,18 \\
\hline $16-17$ & 2 & 0,37 \\
\hline 16 & 4 & 0,74 \\
\hline $15-20$ & 1 & 0,18 \\
\hline 14 & 1 & 0,18 \\
\hline $13-14$ & 1 & 0,18 \\
\hline 3 & 1 & 0,18 \\
\hline
\end{tabular}




\section{Considerações finais}

A edição de periódicos científicos é um desafio importante, sobretudo, quando se almeja ter relevância em uma área específica de História da Educação que possui número considerável de periódicos em âmbito internacional e, ao menos quatro periódicos, de alto nível e consolidados no Brasil. Nesses vinte primeiros anos de publicação de Cadernos de História da Educação, de 2002 a 2021, podemos assinalar aspectos positivos e desafios atuais.

Primeiramente, pode-se destacar positivamente a ampliação do número de artigos publicados anualmente, com salto de uma média de 15 artigos nos primeiros anos para uma média de 45 artigos atualmente. Também é auspicioso que o periódico seja procurado para publicação de dossiês temáticos, o que já alcançou o número de 26 dossiês até o presente momento, com abordagem de diferentes tópicos da História da Educação.

Em segundo lugar, tem sido exitosa a opção recente pela publicação dos artigos em versões bilíngues, com originais predominantemente em português, mas, também, em espanhol e italiano, quase sempre, acompanhados de versões em inglês, o que tem colaborado para a difusão do conhecimento em História da Educação em termos internacionais.

Os objetos de estudo também se mostraram abrangentes e, ainda que predominem publicações sobre o Brasil, foi percebido o tratamento de questões histórico-educacionais de 19 diferentes países nos artigos publicados até o presente momento. Ainda que ocorra concentração da publicação de autores brasileiros, com grande diversidade de procedência institucional, abrangendo todas as regiões do país, também é perceptível que autores vinculados a universidades e a instituições de pesquisa e ensino de outros 17 países tenham publicado artigos no período nos últimos 20 anos, o que demonstra a capilaridade que o periódico tem encontrado em termos internacionais.

Constituem desafios não apenas para o periódico, mas, também, para a área de investigação em História da Educação no Brasil, possibilitar um alargamento das épocas históricas abordadas, dado que existe concentração no Século 20, com alguma ampliação para o Século 19, mas os séculos anteriores ainda carecem de maior adensamento de pesquisas e, por consequência, de artigos publicados.

Outro desafio importante, que se coloca para o periódico, mas, que também incide sobre a pesquisa científica em geral e a educacional em particular, refere-se ao financiamento e à disponibilização de recursos humanos suficientes para a manutenção dos periódicos científicos. Por sorte, Cadernos de História da Educação tem contado com o apoio consistente da UFU e da Fapemig para sua publicação, o que se espera tenha continuidade nos próximos anos. Por fim, há metas de indexação a serem buscadas, para além daquelas já obtidas no país e no exterior, sobretudo, junto aos órgãos de indexação mais consolidados em âmbito internacional.

\section{Referências}

ARAUJO, J.C.S.; Carvalho, C.H.; GATTI JR, D.; INÁCIO FILHO, G.; GONÇALVES NETO, W. O Núcleo de Estudos e Pesquisas em História e Historiografia da Educação da Universidade Federal de Uberlândia: trajetória de pesquisa e contribuição na formação de jovens pesquisadores. Cadernos de História da Educação, v.1, p.11-16, 2002. Disponível em: http://www.seer.ufu.br/index.php/che/article/view/289. Acesso em 15 set. 2021. 
CARVALHO, C.H.; GATTI JR, D.; INÁCIO FILHO, G. ARAUJO, J.C.S.; GONÇALVES NETO, W. História da Educação no Brasil: pesquisa, organização institucional e estratégias de divulgação científica. Cadernos de História da Educação, v.10, n.2, p.45-67, 2011. Disponível em: http://www.seer.ufu.br/index.php/che/article/view/14632. Acesso em 15 set. 2021.

GATTI JR, D. Cadernos de História da Educação (Brazil). In: HERNÁNDEZ HUERTA, J.L.; CAGNOLATI, A.; DIESTRO FERNÁNDEZ, A. (Orgs.). Connecting History of Education. Scientific Journals as International Tools for a Global World. Salamanca: Espanha. FahrenHouse, 2015, p.19-29. Disponível em: https://www.fahrenhouse.com/omp/index.php/fh/catalog/book/14. Acesso em 15 set. 2021.

GATTI JR, D. The role and current challenges of the Brazilian periodical 'Cadernos de História da Educação' in scientific publishing in the History of Education in the twenty-first century. History of Education \& Children's Literature, v.10, n.1, p.29-37, 2015. 